\title{
A IMIGRAÇÃO ALEMÃ E O PROCESSO DE ESCOLARIZAÇÃO EM IJUÍ-RS: da Escola Alemã ao Colégio Sinodal de ljuí (1899 - 1938)
}

\section{LA INMIGRACIÓN ALEMANA Y EL PROCESO DE ESCOLARIZACIÓN EN IJUÍ- RS: de la Escuela Alemana al Colegio Sinodal de ljuí (1899 - 1938)}

\section{GERMAN IMMIGRATION AND THE PROCESS OF SCHOOLING IN IJUÍ-RS: from the German School to the Colégio Sinodal von ljuí (1899 - 1938)}

\author{
Milene Moraes de Figueiredo ${ }^{1}$ \\ https://orcid.org/0000-0002-1566-9204 \\ Eduardo Cristiano Hass da Silva \\ https://orcid.org/0000-0002-3906-5448
}

\begin{abstract}
Resumo
Em 1890, foi fundada a colônia de ljuí, modelo de colônia exemplar, planejada a partir da imigração espontânea e da integração de diversas etnias. O estudo objetiva investigar a aplicação desse projeto de colônia, através do âmbito educacional. Assim, como as mudanças no cenário educacional após a emancipação da colônia em 1912. O enfoque direciona-se para os imigrantes alemães de confissão luterana estabelecidos na região. Analisamos o caso da primeira escola comunitária de origem germânica e confissão evangélica, fundada na colônia, conhecida atualmente como Colégio Evangélico Augusto Pestana. O estudo se insere no campo da História da Educação, com ênfase à História das Instituições Escolares, e utiliza aportes teóricometodológicos da História Cultural. A pesquisa é realizada no Museu Escolar da instituição, e utiliza como fonte os documentos de caráter memorialístico "Relatos do Sr. Albino Brendler" (1995); o livreto "Breve Histórico do Ginásio Augusto Pestana" (1952); e os boletins e livros didáticos referentes ao período analisado. O recorte temporal compreende o período de 1899 a 1938, abrangendo o cenário educacional desses imigrantes desde a fundação da escola até o impacto inicial da implantação das políticas nacionalizadoras do governo estadonovista. A investigação permitiu perceber que inicialmente não foi estabelecido um sistema educacional que assimilasse os imigrantes no contexto nacional. Após 1912, o uso do vernáculo e o ensino da História e Geografia do Brasil foram incentivados sob subvenção estatal, porém, esses incentivos não foram suficientes para evitar uma grande crise em decorrência da política de nacionalização do ensino.
\end{abstract}

\footnotetext{
${ }^{1}$ Doutoranda em História pelo Programa de Pós-Graduação em História da Pontifícia Universidade Católica do Rio Grande do Sul (PUCRS). Bolsista Integral da Capes. Grupo interdisciplinar de estudos do desenvolvimento científico e tecnológico. E-mail: milene.mfigueiredo@gmail.com

${ }^{2}$ Doutor em Educação pela Universidade do Vale do Rio dos Sinos. Professor da Faculdade de Engenharia, Letras e Ciências Sociais do Seridó (FELCS), da Universidade Federal do Rio Grande do Norte (UFRN). Grupo de Pesquisa Turismo, Sociedade \& Território. E-mail: eduardohass.he@gmail.com
}

Como referenciar este artigo:

FIGUEIREDO, M. M. de; SILVA, E. C. H. da. A imigração alemã e o processo de escolarização em ljuí-RS: da Escola Alemã ao Colégio Sinodal de ljuí (1899 - 1938). Revista Pedagógica, v. 23, p. 1-27, 2021. 
Palavras-chave: Educação. História da Educação. História da Educação brasileira. Instituições educativas brasileiras.

\title{
Resumen
}

En 1890 es fundada la colonia de ljuí, modelo ejemplar de colonia, planificada a partir de la inmigración espontánea y de la integración de diversas etnias. El estudio tiene como objetivo investigar la aplicación de este proyecto de colonia, a través del ámbito educativo. Así como los cambios en el escenario educativo tras la emancipación de la colonia. Analizamos el caso de la primera escuela comunitaria de origen germánica y confesión evangélica, fundada en la colonia, actualmente conocida como Colégio Evangélico Augusto Pestana. El estudio se inserta en el campo de la Historia de la Educación, y utiliza aportes teóricos y metodológicos de la Historia Cultural. La investigación se realiza en el Museo Escolar de la institución, y utiliza como fuente los documentos de carácter conmemorativo "Informes del Sr. Albino Brendler" (1995); el folleto "Breve historia del Gimnasio Augusto Pestana" (1952); y boletines y libros de texto del período analizado. El marco temporal comprende el período de 1899 a hasta 1938, abarcando el escenario educativo de estos inmigrantes desde la fundación de la escuela hasta el impacto inicial de la implementación de las políticas nacionalistas del gobierno estatal. La investigación mostró que inicialmente no se estableció un sistema educativo que asimilara a los inmigrantes. Después de 1912, el uso de la lengua vernácula y la enseñanza de Historia y Geografía de Brasil fueron incentivados bajo subsidio estatal, sin embargo, estos incentivos no fueron suficientes para evitar una crisis mayor como resultado de la política de nacionalización de la educación.

Palabras clave: Educación. Historia de la educación. Historia de la educación brasileña. Instituciones educativas brasileñas.

\begin{abstract}
In 1890, the colony of ljuí was founded, an exemplary colony model, planned based on spontaneous immigration and the integration of different ethnic groups. The study aims to investigate the application of this colony project, through the educational scope. As well as the changes in the educational scenario after the emancipation of the colony in 1912. We analyzed the case of the first community school of Germanic origin and evangelical confession, founded in the colony, currently known as Colégio Evangélico Augusto Pestana. The study is inserted in the field of History of Education, and uses theoretical and methodological contributions from Cultural History. The research is carried out at the School Museum of the institution, and uses as a source the memorialistic documents "Reports by Mr. Albino Brendler" (1995); the booklet "A Brief History of the Augusto Pestana Gym" (1952); and newsletters and textbooks for the period analyzed. The time frame covers the period from 1899 to 1938 , covering the educational scenario of these immigrants from the foundation of the school to the initial impact of the implementation of nationalist policies of the state government. The investigation showed that initially an educational system that assimilated immigrants in the national context was not established. After 1912, the use of the vernacular and the teaching of the History and Geography of Brazil were encouraged under state subsidy, however, these incentives were not sufficient to avoid a major crisis as a result of the nationalization policy of education.
\end{abstract}

Keywords: Education. History of Education. History of Brazilian Education. Brazilian educational institutions. 


\section{INTRODUÇÃO}

Durante o século XIX e início do século XX, o Brasil caracterizou-se como um país receptor de imigrantes de diversas nacionalidades. Tanto as parcelas trazidas através de recursos e políticas governamentais, quanto os que chegavam de forma espontânea, costumavam ser redirecionados para núcleos coloniais espalhados pelo país (NEUMANN, 2009). Havia o modelo de colonização público que ocorria através de subvenção do Estado, e o modelo privado, em que o imigrante deveria chegar com os recursos financeiros para arcar com suas despesas e adquirir sua propriedade (NEUMANN, 2009).

A implantação desses modelos de colonização visava solucionar o problema de escassez de mão de obra e promover o preenchimento de "vazios territoriais" incentivando a imigração para regiões desocupadas (SILVA, 2006, p. 250). No caso dos imigrantes alemães ${ }^{3}$, o seu estabelecimento sistemático teve início em 1824, com a criação da colônia de São Leopoldo, no Rio Grande do Sul. Ao longo do século XIX, esses imigrantes e os que iam chegando passaram a formar as "colônias velhas ou antigas" também conhecidas como região colonial alemã (e italiana), ocupando a colônia de São Leopoldo e estendendo-se gradualmente até os vales dos rios Sinos, Caí e Taquari (NEUMANN, 2009, p. 15).

Os imigrantes alemães, traziam consigo, além de uma bagagem material para regiões até então desocupadas, um acervo cultural "representado por todas as características comuns - o idioma, o amor pela pátria distante, o sentimento de nação, uma filosofia de vida gregária, o pragmatismo e o gregarismo" (BASTOS, 2016, p. 139). Somando essas características a questão da falta de estímulos e de estrutura que proporcionasse à integração desses imigrantes à população nacional, uma parcela significativa destes, foram criando suas próprias igrejas, escolas e clubes recreativos que tinham em comum a característica de preservação da língua materna.

\footnotetext{
${ }^{3}$ Ressaltamos que quando nos referimos aos imigrantes alemães, na verdade estamos fazendo referência aos imigrantes remanescentes de diferentes regiões da Alemanha setentrional e ocidental (estados alemães pré-unificação), da Áustria, Rússia, Polônia, assim como outros países. (WILLENS, 1946, p. 62).
} 
No início do século XX, a elite intelectual brasileira deu ênfase ao debate da questão racial no país ${ }^{4}$. Vendo a massa de escravizados egressos nas grandes propriedades como um problema, propuseram a tese do "branqueamento"5 da população como a solução mais rápida. Objetivavam assimilar o imigrante branco europeu, fundindo-o com o nacional garantindo "por meio dessa alquimia redentora, a homogeneidade e uniformidade dos habitantes, finalmente libertos de sua ancestral inferioridade e transmutados em um verdadeiro povo" (LUCA, 2004, p. 45-46).

Como após a Proclamação da República, houve uma redução das verbas nacionais direcionadas ao incentivo à imigração e colonização, a iniciativa passou a ser de responsabilidade de cada estado. Segundo Schwarcz e Starling (2015), considerando que no Sul do país existiam extensas áreas não ocupadas, é possível observar características distintas de imigração de acordo com as regiões. Para Neumann (2009), esse período marcou o início da colonização da metade Norte do estado, quando as iniciativas públicas e particulares se preocuparam em atender à demanda dos colonos por terras, solucionando problemas como o excedente populacional e o esgotamento do solo da antiga zona de colonização alemã e italiana. Nesse contexto, foi fundada em 1890, no município de Cruz Alta, a colônia de ljuí, um "protótipo de colônia etnicamente mista e planejada, provida pela imigração espontânea, modelo desejado a partir de então" (NEUMANN, 2009, p. 15).

A ideia de implantação desse modelo de colônia mista surgiu como uma estratégia de, para além de estimular a imigração e o branqueamento, promover uma assimilação mais rápida dos elementos estrangeiros em território nacional. Acreditava-se que assim os isolamentos em comunidades étnicas poderiam ser evitados. Essa proposta ia de encontro às

[...] ideologias nacionalistas difundidas no Brasil desde no mínimo o início da República, que ganharam força na década de vinte e se impuseram com o Estado Novo a partir de 1937, consideravam que uma rígida campanha de "nacionalização" garantiria o estabelecimento definitivo da unidade e

\footnotetext{
${ }^{4}$ Conforme destacam Lilia M. Schwarcz e Heloisa M. Starling (2015), teorias como o darwinismo social e a antropologia criminal faziam sucesso no país. Dessa forma, identifica-se a concepção de que as raças correspondiam a dados essenciais e fixos, sendo a humanidade dividida a partir delas. Dentro desta divisão, os brancos caucasianos estariam no topo da pirâmide e, os negros, na base.

${ }^{5}$ Sobre o tema ver Luca (2004).
} 
homogeneidade étnico-cultural-religiosa no Brasil e que a partir deste momento o quadro brasileiro estava definido (GERTZ, 1991, p. 7).

Ainda segundo o autor, a história brasileira "mostra que, além das desigualdades entre regiões e estratos sociais, a homogeneidade étnico-cultural está longe de ser uma realidade" (GERTZ, 1991, p. 7). Além disso, os alemães foram um dos maiores alvos das políticas nacionalizadoras. Considerando essas duas questões, o presente estudo investiga a aplicação desse projeto de colônia multiétnica, na prática, através do âmbito educacional. Assim, como as mudanças no cenário educacional após a emancipação da colônia que se tornou município em 1912. O enfoque direciona-se para o caso específico dos imigrantes alemães de confissão luterana estabelecidos na região. Para tanto, analisamos o caso da primeira escola comunitária de origem germânica e confissão evangélica, fundada na então colônia. A instituição é conhecida atualmente como Colégio Evangélico Augusto Pestana, sendo uma escola privada, ligada à Comunidade Evangélica ljuí e filiada à Igreja Evangélica de Confissão Luterana no Brasil - IECLB ${ }^{6}$.

A análise é feita a partir das seguintes questões direcionadoras: O cenário da implantação da colônia favoreceu o estabelecimento de um sistema educacional que assimilasse os imigrantes alemães no contexto nacional? Ocorreram políticas de incentivo por parte do Estado que proporcionassem a alfabetização em língua portuguesa? Quais os impactos da emancipação da colônia para o âmbito educacional? Os imigrantes alemães conseguiram promover a manutenção da identidade teuto-brasileira, da língua materna e da confissão luterana nesse projeto de colônia exemplar? A inserção desses imigrantes nesse cenário facilitou o processo de nacionalização implantado no Estado Novo?

O estudo se insere no campo da História da Educação, com ênfase à História das Instituições Escolares, e utiliza aportes teóricos da História Cultural. A pesquisa é realizada no Museu Escolar7 da instituição, e utiliza como fonte documentos que integram a cultura empírica e material da escola (ESCOLANO BENITO, 2017): os documentos de caráter memorialístico "Relatos do Sr. Albino Brendler” (1995); o livreto “Breve Histórico do Ginásio Augusto Pestana” (1952); e os boletins e livros didáticos

\footnotetext{
${ }^{6}$ A escola integra a Rede Sinodal de Educação, sendo mantida pela Instituição Sinodal de Assistência, Educação e Cultura - ISAEC.

${ }^{7}$ Sobre o Museu escolar do Colégio Evangélico Augusto Pestana, ver Leonardo Borcini (2012).
} 
referentes ao período analisado salvaguardados no acervo. Privilegiou-se a análise ${ }^{8}$ dos documentos memorialísticos, que trazem mais indícios acerca do período analisado, sendo as demais fontes utilizadas de forma suplementar. A partir do cruzamento dessas fontes buscamos aproximações com elementos que integravam a cultura escolar da instituição no período analisado. O recorte temporal compreende o período de 1899 a 1938, abrangendo o cenário educacional desses imigrantes desde a fundação da escola até o impacto inicial da implantação das políticas nacionalizadoras do governo estadonovista.

Além da introdução e das considerações finais, dividimos o texto em três partes: $\mathrm{Na}$ primeira discorremos sobre a História da educação como campo de pesquisa mobilizando a História das Instituições escolares e o conceito de cultura escolar. A seguir, na segunda e terceira parte, respetivamente, analisamos a história da instituição em dois contextos distintos: De sua fundação até o contexto de emancipação da colônia de ljuí (1899-1912); Das mudanças impulsionadas pelo novo município até o início da política de nacionalização do ensino (1912-1938). Procuramos enfatizar as mudanças no cenário educacional, situando o contexto em que a escola estava inserida em cada período.

\section{A HISTÓRIA DA EDUCAÇÃO E HISTÓRIA DAS INSTITUIÇÕES ESCOLARES EM DIÁLOGO COM O CONCEITO DE CULTURA ESCOLAR}

Ao longo do século $\mathrm{XX}$, especialmente a partir das discussões propostas pela revista francesa Annales d'Histoire Économique et Sociale, fundada em 1929 por March Bloch e Lucien Febvre, observa-se um processo de ampliação das problemáticas, fontes e temáticas da História. Segundo Prost (2015), essa ampliação da disciplina deve-se, em especial, ao diálogo estabelecido com outras disciplinas, como a Geografia. Além disso, observa-se ainda o deslocamento de uma análise centrada na História Política e na fixação de personagens/eventos para uma História Social e Cultural. De acordo com Stephanou e Bastos (2005), a emergência da Escola dos Analles, interferiu diretamente na História da Educação, ampliando as suas problemáticas de investigação.

\footnotetext{
${ }^{8}$ Ressaltamos que a análise foi feita levando em consideração os cuidados da Ética e pesquisa em Educação.
} 
$\mathrm{Na}$ perspectiva das autoras, entendemos que, enquanto campo de pesquisa, a História da Educação não é uma ciência à parte, uma vez que não possui um campo analítico exclusivo, estando seu potencial teórico e metodológico justamente no fato de encontrar-se em uma área de intersecção entre a História e a Educação. É nesta área de intersecção que o presente estudo se fundamenta.

O caráter de fronteira do campo histórico educativo é reforçado por Magalhães (2004). Entendendo a História da Educação como parte das Ciências da Educação, o autor afirma que matriz interdisciplinar deste campo se fundamenta na polissemia e na complexidade do conceito de Educação. Dentro destas concepções, é possível afirmar que a História da Educação comporta vários temas e objetos de pesquisa, como: a história do ensino; a história dos livros, impressos e manuais didáticos; a história das crianças, das infâncias, dos jovens e das mulheres; a história das instituições educativas escolares e não-escolares; a história do currículo e das reformas educativas; entre outros (STEPHANOU, BASTOS, 2005; MAGALHÃES, 2004).

Dentro da diversidade de fontes e problemáticas possíveis, este estudo centra-se nos processos educativos de imigrantes alemães no Rio Grande do Sul, especialmente a partir do então chamado Colégio Evangélico Augusto Pestana. A atenção especial para uma instituição, aproxima-nos da temática da História das Instituições Educativas, que, de acordo com Nosella e Buffa (2009), a partir dos anos 1990, ganhou espaço no Brasil, colocando em crise paradigmas e ampliando fontes e linhas de pesquisa.

Considerando o referencial teórico empregado e o campo no qual esta pesquisa encontra-se, mobilizamos o conceito de cultura escolar em nossas análises. De acordo com Viñao Frago (2006), embora as origens das culturas escolares encontrem-se atreladas ao surgimento da escola enquanto instituição, o conceito "cultura escolar" passa a ser utilizado a partir dos anos 1990, sobretudo no âmbito da História Cultural e do Currículo, sendo um dos seus precursores o pesquisador Dominique Julia. Para este, o conceito de cultura escolar pode ser pensado em uma perspectiva histórica, sendo mobilizado para sistematizar as normas, saberes, ritos e mitos escolares.

De forma geral, Viñao Frago (2006) considera mais adequado falar sobre culturas escolares, no plural, considerando que há várias culturas circulando em diferentes 
espaços e que cada instituição constrói sua própria cultura. Para o autor, o conceito expressa um:

[...] conjunto de teorías, ideas, principios, normas, pautas, rituales, inercias, habitos y prácticas (formas de hacer y pensar, mentalidades y comportamientos) sedimentadas a ló largo del tiempo en forma de tradiciones, regularidades y reglas de juego no puestas en entredicho, y compartidas por sus actores, en el seno de las instituiciones educativas. Tradiciones, regularidades y reglas de juego que se transmiten de gereración en generación y que proporcionan estrategias $[\ldots]($ VIÑAO FRAGO, 2006, p. 73).

O conceito apresentado permite entender a cultura escolar a partir de elementos marcados pela continuidade, estabilidade, sedimentação e autonomia em relação ao universo escolar. Viñao Frago (2006) destaca ainda que existem quatro aspectos ou elementos que são mais visíveis na cultura escolar, sendo eles os atores, discursos, aspectos organizativos e a cultura material da escola. No presente estudo, estes quatro aspectos foram, sempre que possível, analisados, uma vez que potencializam a possibilidade de compreensão das questões relacionadas ao Colégio Evangélico Augusto Pestana.

Assim como Viñao Frago (2006), outro autor que contribui para pensar e fundamentar o conceito de cultura escolar é Augustín Escolano Benito (2002, 2017). Para ele, a definição de Cultura Escolar refere-se a três âmbitos da memória da educação: modalidade empírica, modalidade científica/acadêmica e cultura política. Em relação à modalidade empírica da Cultura Escolar, o autor entende-a como os registros da cultura empírico-prática feitos pelos sujeitos de dentro das instituições educativas. Essa modalidade comporta os artefatos materiais das instituições escolares e as práticas cotidianas deste espaço (BENITO ESCOLANO, 2002; 2017).

Por artefatos materiais, são entendidos os diferentes objetos salvaguardados em arquivos, memorias, museus escolares, entre outros. Em relação às práticas, destaca-se a importância dos rituais escolares, uma vez que "a cultura empírica da escola é, em grande medida, formada por uma cadeia de rituais internos de interação e ao mesmo tempo condicionada pelas ritualidades do mundo da vida" (BENITO ESCOLANO, 2017, p. 86). A análise dos artefatos materiais e das práticas cotidianas permitem identificar a escola como um mecanismo produtor de cultura. 
É sobre a cultura empírica da educação que este estudo se debruça, especialmente sobre os documentos salvaguardados no Museu Escolar da instituição. É sobre a História dessa instituição, situada na cidade de ljuí, no Rio Grande do Sul, que discorremos na sequência.

\section{A FUNDAÇÃO DA COLÔNIA DE IJUÍ E O INÍCIO DO PROCESSO DE ESCOLARIZAÇÃO: A FUNDAÇÃO DA PRIMEIRA ESCOLA PARTICULAR (1899-1912)}

A memória enquadrada (POLLAK, 1989) pela instituição, aponta duas datas distintas de fundação da escola: a primeira refere-se ao ano de 1899 quando a Comunidade Evangélica fundou uma escola que ficou conhecida como "Primeira Escola Particular de Ijuí". Em novembro de 1912, ocorreu uma separação somente no âmbito administrativo entre a escola e Igreja, quando foi criada a Sociedade Escolar Alemã, que passou a atuar como mantenedora da instituição. A partir dessa mudança, foi demarcada a fundação da "Segunda Escola Particular de ljuí", sendo a escola fundada pela comunidade evangélica considerada a sua percursora.

Considerando que foi apenas uma mudança de ordem administrativa e que a escola não rompeu com sua identidade confessional, adotamos aqui a perspectiva de Brandt (2009), que demarca 1899 como o ano de fundação da escola. Para compreender o processo de fundação da instituição, situamos brevemente o contexto e cenário educacional em que a escola foi inserida.

A colônia de ljuí foi fundada em 1890, como parte integrante do município de Cruz Alta e tinha como característica predominante seu caráter multiétnico, sendo habitada inicialmente por alemães, teuto-russos, austríacos, húngaros, poloneses, romenos, entre outras nacionalidades. Conforme já foi ressaltado, esse sistema tinha como objetivo favorecer o processo de assimilação dos imigrantes, evitando assim a formação de quistos étnicos. Porém, apesar da idealização de um sistema que supostamente contribuiria para o projeto político de construção de um modelo de nação brasileira, a colônia foi fundada e verificou-se a reprodução de um padrão característico dos primórdios das "colônias velhas ou antigas": a precariedade de recursos e a falta de 
escolas públicas que oferecessem educação pública em língua portuguesa para os filhos desses imigrantes.

De acordo com Rosa, Trennepohl e Carneiro (2017), ao chegar na colônia em 1890, a primeira preocupação dos imigrantes foi a organização das moradias e da produção de subsistência. Segundo Siedenberg (1952), três anos após o início da colonização apenas duas ruas estavam abertas, estando o restante coberto por mata virgem. Somaram-se a essas dificuldades iniciais, a eclosão da Revolução Federalista9 (1893-1895) que contribuíram para que houvesse um atraso da passagem da colônia para administração local (BRANDT, 2009, p. 31).

Diante desse contexto, as primeiras notícias do processo de escolarização remetem ao ano de 1894, com as aulas particulares de Robert Roeber, professor de origem alemã, que se dedicava a alfabetização e educação dos meninos da colônia. Atendia em classes multisseriadas os filhos dos imigrantes que dominavam a língua alemã. As aulas ocorriam nos fundos de um espaço improvisado conhecido como Barracão, construído para abrigar as primeiras famílias de imigrantes recém-chegadas (Rosa, Trennepohl; Carneiro; 2017, p. 5-6). Apesar do caráter particular das aulas, esse espaço foi considerado a primeira escola pública de ljuí. Rober foi nomeado oficialmente professor público em 1895. Para educação das meninas foi contratada a professora normalista Belmira Gonçalves Terra (SIEDENBERG, 1952, p. 5).

De acordo com Albino Brendler'10 (1995, p. 7) a escola "era um simples galpão aberto de madeira sem janelas. Estava tão cheia de crianças que não podia mais ser aceita nenhuma". Tratava-se de um espaço de escolarização improvisado, marcado pela precarização de recursos e pelos esforços dos próprios sujeitos que habitavam a colônia. Portanto, não havia, nesse momento inicial, incentivo do âmbito estatal para que os filhos dos imigrantes recebessem uma educação de qualidade, o que afetou o projeto político de plena integração entre sujeitos de diferentes etnias através do uso do vernáculo.

\footnotetext{
9 A Revolução Federalista (1893-1895) foi uma guerra civil protagonizada em solo gaúcho. O conflito foi disputado entre os Federalistas (maragatos) e o Republicanos (pica-pau).

${ }^{10}$ Os relatos do Sr. Albino Brendler contemplam suas memórias sobre a Comunidade Evangélica de ljuí, a história da então Escola Particular de ljuí, assim como as mudanças ocorridas em ljuí desde sua chegada na colônia, até a década de 1950. Utilizamos aqui a versão traduzida por Erica Ziegler e encadernada pelo Museu Escolar em 1995.
} 
Em 1895, os imigrantes alemães de confissão evangélica fundaram a Comunidade Evangélica de ljuí (Deutsch Evangelische Gemeinde von ljuhy). A comunidade surgia num contexto em que o Sínodo Rio-grandense ${ }^{11}$, fundado em 1886, estava trabalhando pela manutenção de uma identidade coletiva dos grupos heterogêneos de imigrantes alemães e teuto-brasileiros espalhados pelo Sul do Brasil, mas que tinham a confissão religiosa e o uso da língua alemã como elementos de identificação. Um dos símbolos da aliança entre luteranismo e germanidade demarcados pelo sínodo, era a língua alemã, que aproximaria os evangélicos de Deus através da leitura da Bíblia (Meyer, 2000). Dessa forma, o sínodo incentivava a criação e manutenção de escolas confessionais que teriam um papel essencial no cultivo de elementos do germanismo como a língua e o espírito alemão, atrelados a questão religiosa (WACHHOLZ; SCHMIDT, 2012, p. 1633).

Inserida nesse contexto de crescente influência do Sínodo Riograndense, e diante da precária estrutura da escola pública da região, que não estava mais conseguindo dar conta das demandas, nem do número de estudantes, a Comunidade Evangélica de ljuí fundou a primeira escola particular da colônia. A instituição foi fundada em 1899 dando início a uma relação intrínseca entre escola e igreja, instituições que de acordo com o Koch (2003, p. 200), atuavam como importantes mecanismos de autoconservação dos teuto-rio-grandenses, apoiando-se mutualmente.

O pequeno espaço de ensino aproximava-se a tipologia de escola evangélica definida por Koch (2003) como Gemeindeschulen, um dos primeiros modelos de escola comunitária de confissão evangélica surgidos durante o século XIX, fazendo-se presente na colônia de ljuí no início do século XXI:

[...] as criadas por comunidades individuais para assegurar uma educação cristão-evangélica aos filhos de seus membros. Foram elas as primeiras a surgir, na falta de um sistema educacional oficial suficientemente abrangente, oferecendo de início apenas o ensino fundamental. $(\mathrm{KOCH}, 2003$, p. 193)

A escola foi instalada em um casebre emprestado pelo sr. Luiz Keller e os bancos e carteiras foram fabricados gratuitamente pelo Sr. Albino Brendler. A classe multisseriada composta por 12 alunos foi assumida por um professor de origem alemã chamado Max

\footnotetext{
${ }^{11}$ Sobre o Sínodo Rio-grandense ver Dreher (2003).
} 
Trauning. Sua pensão era fornecida pelos membros fundadores ${ }^{12}$ (BRANDT, 2009, p. 12). A mensalidade era de $\mathrm{Cr} \$ 1,50$ por aluno, cabendo ao professor $\mathrm{Cr} \$ 0,40$ de cada. Identificar e analisar a materialidade do local no qual a instituição estava inserida se torna potente para a compreensão da cultura escolar que ali foi construída (NOSELLA; BUFFA, 2009; ESCOLANO BENITO, 2002; 2017). Dessa forma, ressaltamos esses elementos ao longo do estudo, visando uma melhor compreensão da cultura escolar ali construída.

Albino Brendler, registrou em seu livro de memórias algumas reminiscências sobre a fundação da escola:

\begin{abstract}
Quando eu já morava há algumas semanas aqui em ljuí, fui procurado por um homem para fundar uma escola. [...] vários pais de família decidiram fundar uma escola particular. Já que eu ainda era novo ali, aquele homem estava me procurando para ajudar na fundação dessa escola. Apesar de não ter ainda filhos em idade escolar, prontamente me dispus a ajudar. Como professor eles tinham em vista um jovem alemão que recém tinha chegado de lá. A escola foi instalada em um galpão de madeira. Também apareceu um monte de crianças, assim que a escola logo pôde começar. Mas onde colocar o professor? Foi resolvido que teria seu quarto na própria escola e a alimentação em famílias diversas. A alimentação foi assumida por quatro famílias: Karl Hintz, Zöllner, Brendler e Finster. Nessas famílias ele recebia as refeições no rodízio mensal. (BRENDLER, 1995, p. 7).
\end{abstract}

De acordo com Magalhães (2004, p. 67), no campo da história das instituições escolares, a instituição e a educação se articulam através das ações dos sujeitos. O relato de Brendler, nos permite observar que essa escola comunitária, teve seu cotidiano escolar marcado desde o início por constante atuação de seus membros, que auxiliaram cedendo espaços, construindo o mobiliário escolar, encarregando-se da alimentação do professor, entre outras ações cotidianas. Essas ações incidiram diretamente sobre a materialidade dos espaços em que a escola foi inserida ao longo do tempo.

Rapidamente o número de alunos cresceu, tornando necessário o investimento na ampliação do mobiliário escolar para a acomodação de mais crianças. Porém, após apenas dois anos, o professor precisou se afastar por motivo de saúde e o funcionamento da escola foi interrompido. De acordo com Koch (2003), a falta de professores era um problema recorrente nas escolas comunitárias:

\footnotetext{
12 Seus fundadores foram os membros Albino Brendler, Carlos Hinzt, Júlio Otto Geiss, Albino Finster e Luiz Keller (SIEDENBERG, 1952).
} 
Embora as comunidades considerassem a construção de uma escola uma das tarefas prioritárias, executadas frequentemente sob forma de mutirão, nem sempre foi fácil desenvolver um ensino eficiente pela falta de professores devidamente preparados (KOCH, 2003, p. 202-203).

A Comunidade Evangélica só voltou a fornecer ensino em 1903, com a chegada do pastor Germano Rosenfeld que assumiu as funções de pároco e professor da comunidade. As aulas ocorriam na casa canônica, recebendo a denominação de "Escola Paroquial”. A escola deu início às atividades com uma classe multisseriada, abrindo mais uma no turno inverso assim que a demanda começou a crescer. Além do pastor Rosenfeld, lecionaram na escola o professor Henrique Siedenberg, atuando como substituto no ano de 1908, e a professora Hulda Scherer que passou a atuar como auxiliar, a partir de 1912.

A escola permaneceu a cargo da comunidade evangélica até o ano de 1912, quando a escola Paroquial foi transformada em "Sociedade Escolar Alemã", tendo Roberto Low e Albino Brendler como seus dirigentes. Porém, manteve a característica de escola templo até o ano de 1914, quando decidiram que as atividades religiosas e educacionais deveriam ocorrer em espaços diferentes. (SIEDENBERG, 1952).

De acordo com Aragão e Freitas (2011, p. 166-167), "abrir os portões de uma escola significa entrar em um universo complexo, imerso numa rede de relações e significações que envolve sujeitos, artefatos, tempos e espaços". Devido à escassez de informações disponíveis, sobre esse período inicial, nos deparamos com uma série de lacunas acerca da complexidade do cotidiano escolar. Ainda assim, a partir das fontes memorialísticas, foi possível discriminar alguns elementos relevantes para a análise.

A manutenção de um espaço de ensino para os filhos dos imigrantes instalados na colônia, foi resultado dos esforços da Comunidade Evangélica no cultivo da identidade confessional da comunidade, que tinha a alfabetização em língua alemã como um elemento importante na manutenção de um "espírito" alemão, e para melhor compreensão divina através da leitura da Bíblia na língua materna. De 1899 a 1912 a escola contou com três professores e uma professora, todos de origem europeia conforme o quadro um. 
Quadro 1 - Relação dos professores que atuaram no estabelecimento de 1899 a 1912.

\begin{tabular}{|c|c|}
\hline Professores & Período de atuação \\
\hline Max Traunig & $1899-1900$ \\
\hline P. Germano Rosenfeld & $1903-1912$ \\
\hline Henrique Siedenberg & 1908 \\
\hline Hulda Scherer & 1912 \\
\hline
\end{tabular}

Fonte: Quadro elaborado pelos autores (2021).

O quadro um, elaborado a partir de Siedenberg (1952), permite identificar o nome e o período de atuação dos professores na instituição: Max Traunig, entre 1899 e 1900; P. Germano Rosenfeld entre 1903-1912; Henrique Siedenberg em 1908 e Hulda Scherer. Embora entendamos a importância de situar estes professores no contexto da cultura escolar, o caráter lacunar das fontes ainda não nos permite maiores informações sobre eles, deixando espaço para investigações futuras.

Esses professores também foram alojados em espaços improvisados, passando por constantes mudanças de moradia e alimentação. Conforme Meyer (2000) essa situação era comum, considerando que nesse período, a profissão de professor primário não era muito valorizada na perspectiva material, sendo muitas vezes vista como uma alternativa de trabalho marcada por instabilidade, provisoriedade e baixa remuneração.

Quanto ao número de alunos, a escola iniciou com 12. O número cresceu ao longo do tempo, mas regrediu para 11 estudantes quando o professor P. Germano Rosenfeld fez uma viagem sendo substituído pelo professor Henrique Siedenberg. Logo os estudantes se acostumaram com o novo professor e o número de matrículas foi superior às dos anos anteriores, chegando à casa dos 70 alunos e aumentando para 90 quando o professor Germano Rosenfeld assumiu as aulas novamente ${ }^{13}$ (Siedenberg, 1952).

Quadro 2 - Relação dos alunos matriculados entre 1899-1910

\begin{tabular}{|c|c|}
\hline Ano & Número de alunos \\
\hline 1899 & 12 \\
\hline 1908 & 11 \\
\hline $1908-1909$ & 70 \\
\hline 1910 & 90 \\
\hline
\end{tabular}

Fonte: Quadro elaborado pelos autores (2021).

\footnotetext{
${ }^{13}$ Esse estudo não objetiva aprofundar dados específicos sobre os índices populacionais de ljuí, nem sobre o desenvolvimento da colônia, mas indicamos a obra de Brand (2009) que no capítulo II, trabalha com alguns indícios acerca do desenvolvimento da colônia nesse período. Sua análise traz algumas pistas que podem impulsionar estudos futuro sobre a variação do número de alunos nesse período.
} 
Nesse primeiro momento, a escola ofertava somente o ensino do alemão. Conforme Siedenberg (1952), os imigrantes mal falavam ou desconheciam o português. Este era o caso não apenas dos imigrantes de origem alemã que ali residiam, mas também dos teuto-russos, austríacos, húngaros, poloneses, romenos, entre outros, que se comunicavam em alemão, trazendo um caráter germânico à colônia. (BRANDT, 2009).

Apesar das expectativas e idealizações, estabeleceu-se na colônia de ljuí, em seus primeiros anos, um cenário recorrente nas "colônias velhas": o estabelecimento de escolas comunitárias com forte conotação étnica e marcadas por confissões cristãs (KREUTZ, 2000, p. 159). No caso de ljuí, esta era ainda, a única escola privada, mas seguia essas características.

Paralelamente ao âmbito educacional, a colônia passou a se desenvolver mais rapidamente com o fim da Revolução em 1895, e principalmente a partir 1900, quando sua direção foi confiada a Augusto Pestana, conhecido na região como o primeiro diretor da colônia. Em 1912, a colônia transformou-se em Vila e Município, a partir desse momento ocorreram modificações e incentivos no âmbito escolar, e a escola passou a receber subvenção estatal para o ensino do vernáculo, conforme abordamos nas páginas a seguir.

\section{A EMANCIPAÇÃO DA COLÔNIA E AS MUDANÇAS NO CONTEXTO EDUCACIONAL: DA ESCOLA ALEMÃ AO COLÉGIO SINODAL (1912-1938)}

Em 1912, a colônia de ljuí emancipou-se politicamente do município de Cruz Alta, passando a ser considerada uma Vila e Município. A partir desse momento, o olhar do município sob o setor educacional, acabou impulsionando mudanças dentro da instituição. Em 1914, foi construído o primeiro prédio próprio da escola, que consistia em uma construção de madeira, com três salas de aula separadas por paredes de alvenaria, atualmente conhecido na escola como "Escolinha da Roça". O espaço foi construído em três lotes urbanos disponibilizados pelo município, doados por Augusto Pestana ${ }^{14}$ e regularizados pelo Cel. Soares de Barros.

\footnotetext{
${ }^{14}$ Em de 1946, quando a escola precisou atender a determinação da Secretaria de Educação que exigia a
} designação de "Escola" juntamente com um vulto nacional, Augusto Pestana foi escolhido como patrono 
Além disso, ao fundar a "Sociedade Escolar Alemã”, que assumiu a manutenção da escola, os dirigentes Roberto Low e Albino Brendler implementaram o ensino do vernáculo na escola através de subvenção estatal. O intendente Cel. Soares de Barros encaminhou para a escola a professora Maria Amorim, que receberia do município um ordenado de Cr\$100,00 para lecionar as disciplinas de Português, História e Geografia do Brasil. (SIEDENBERG, 1952, p. 7). Assim, essa atenção do município para com a escola, se incidiu sobre a materialidade e sobre o currículo da instituição.

Em 1952, a então professora concedeu um relato ${ }^{15}$ para o livreto memorialístico “Breve Histórico do Ginásio Evangélico Augusto Pestana" (SIEDENBERG, 1952), referindose à instituição como “Colégio Alemão" e “Escola Alemã”, narrou suas experiências:

Recém-saída da meninice, possuindo apenas conhecimentos adquiridos em cursos primários e por esforço próprio, como autodidata que sempre fui, mas já impulsionada por irresistível vocação de ensinar, contratou-me o benérito intendente e grande benfeitor de ljuí - o Coronel Dico - para ministrar rudimentos da Língua Portuguesa, História e Geografia do Brasil aos alunos dessa Escola, todos de origem alemã, afim de se cumprirem nossas leis que já proibiam colégios de língua estrangeira que não ensinassem o idioma do país. (AMORIM, 1952 in SIEDENBERG, 1952, p. 31)

Kreutz (1991), aponta que a implementação do ensino da língua portuguesa encontrou resistências, protagonizando conflitos nas escolas étnicas voltadas para as comunidades de ascendência alemã que por vezes não aceitavam a proposta, nem sob subvenção estatal. Sob a perspectiva pedagógica, utilizava-se a alegação de que uma educação bilíngue poderia prejudicar o aprendizado dos estudantes que não aprenderiam de forma satisfatória nem o português nem o alemão. Além disso, havia a difusão do discurso de que o surto de desenvolvimento religioso entre os teuto-brasileiros devia-se a preservação da língua e das tradições alemãs. Essa identificação estava presente tanto nas comunidades evangélicas quanto nas católicas jesuítas, tendo um peso maior para os primeiros.

da instituição. Assim, o nome do estabelecimento foi alterado de "Colégio Sinodal" para "Escola Sinodal Augusto Pestana" (Siedenberg, 1952).

15 O livro analisado não apresenta muitas informações a respeito de sua publicação, não sendo possível esmiuçar maiores detalhes. A partir de sua análise é possível aferir que a professora enviou um relato que foi publicado na íntegra. 
No caso da instituição analisada, não há registros de conflitos, somente de negociações e boas relações entre a "Sociedade Escolar Alemã" e a administração municipal de ljuí. Entretanto, o papel da nova professora ia além da perspectiva curricular, ainda de acordo com seu relato:

[...] inspirava-me o desejo ardente de conquistar meus alunos, roubando-lhes um pouco da grande admiração que dedicavam à Pátria de seus pais e avós. Queria fazê-los conhecer melhor e amar mais estranhamente a jovem Pátria brasileira, que tanto era minha como deles, como berço abençoado e dadivoso. E assim se passaram cinco longos anos de luta constante para a jovem e modesta professorinha brasileira que fez de sua tarefa quotidiana de ensinar um comovente drama de aliciamento patriótico, de luta nacionalizadora, na ânsia de abrasileirar, de aperfeiçoar nos conhecimentos da Pátria essas almas em flor rica e prometedora seara humana para os celeiros do Brasil (AMORIM, 1952 in SIEDENBERG, 1952, p. 31).

De acordo com Morch (1988, p. 254), o alvo mais visado da campanha de nacionalização implementada durante o governo estadonovista, era a escola primária particular, e seu principal agente era o professor público, responsável pela promoção do conhecimento da língua e pelo culto às tradições nacionais. A partir do relato da professora Amorim, parece que, já em 1912, existia um discurso que vinculava seu papel como docente à uma "missão nacionalizadora". Tal afirmação deve, porém, levar em conta o processo de construção da memória e, sua articulação entre lembranças e esquecimentos. Dessa forma, ao rememorar os anos 1912, a professora sistematiza suas lembranças a partir de uma vida, trazendo apontamentos sobre o período.

Dessa forma, podemos pensar que, se por um lado, o município prestou auxílios significativos à escola cedendo lotes urbanos e disponibilizando uma professora, por outro, o investimento no âmbito educacional, com incentivo ao ensino do vernáculo e das disciplinas de História e Geografia do Brasil, ia ao encontro dos ideais assimilacionistas preconizados desde o período de fundação da colônia. Verificamos assim, a partir da emancipação do município um cenário que incentivava a alfabetização e língua portuguesa e uma maior integração dos imigrantes e descendentes no cenário nacional.

A escola por sua vez, demonstrava um colaboracionismo esses ideais, porém, desfrutando da liberdade de ensino proporcionada naquele momento, o fazia sem abrir mão da preservação da língua, da cultura e do "espírito alemão", elementos que nesse 
contexto também estavam atrelados à confissão luterana. Ainda de acordo com o relato da professora, os demais professores eram todos de origem europeia, e a escola estava sob direção de pastores luteranos, o que demonstra a continuidade na manutenção do vínculo com a comunidade evangélica.

O convívio com professores europeus, sob a direção de pastores luteranos, cultos e de adiantados conhecimentos pedagógicos, trazidos da Alemanha, exerceu sobre minha carreira de mestra uma duradoura e benéfica influencia (AMORIM, 1952 in SIEDENBERG, 1952, p. 31).

Sobre as práticas pedagógicas inspiradas no cenário alemão, Brandt (2009, p. 65), afirma que sendo dirigida somente por diretores de nacionalidade alemã, e contando com professores de nacionalidade alemã, ou teuto-brasileiros, as práticas pedagógicas continham um "forte cunho de germanidade". Não foram localizados registros anuais com a grade curricular da escola, mas, através do cruzamento das informações contidas no livreto organizado por Siedenberg (1952), e boletins escolares salvaguardados no museu escolar, foi possível obter alguns indícios.

De acordo com as informações discriminadas no boletim escolar de um estudante que frequentava a instituição no ano de 1914, o currículo era composto pelas seguintes disciplinas: Deutsche Sprache (língua alemã); Portugiesische Sprache (língua portuguesa); Rechnen (Aritmética); Geometrie (Geometria); Geographie (Geografia); Geographie und Geischchte von Brasilien (Geografia e História do Brasil); Allgemeine Geichichte (História geral).

A partir do acompanhamento dos boletins de mais dois estudantes, sendo que um deles registra o acompanhamento anual de um menino de 1915 a 1922, e o outro pertenceu a uma menina que frequentou a instituição de 1921 a 1925, é possível discriminar as disciplinas lecionadas em cada série: durante o primeiro e o segundo ano do curso primário, o ensino era dedicado à alfabetização em língua alemã, língua portuguesa e ao ensino das primeiras contas, restringindo-se à três disciplinas: Deutsche Sprache (língua alemã); Portugiesische Sprache (língua portuguesa); Rechnen (Aritmética). A partir do terceiro ano, além das disciplinas já mencionas, era introduzido o ensino de mais duas: Geographie (Geografia) e Naturgeschichte (História do Natural). 
A partir do curso secundário, havia uma ampliação do currículo escolar, que se dividia em sete disciplinas: Deutsche Sprache (língua alemã); Portugiesische Sprache (língua portuguesa); Rechnen (Aritmética); Geographie (Geografia); Brasilianiche Gechichte (História brasileira); Deutche Gechichte (História Alemã); - Naturgeschichte (História do natural).

Quanto ao processo de avaliação dos alunos, as notas eram dadas através dos seguintes conceitos: 1. fehr gut (muito bom); 2. gut (bom); 3. genügend (suficiente); 4. mangelhalft (inadequado); 5. ungenüngend (insuficiente). Os alunos eram avaliados não apenas pelos resultados obtidos em cada disciplina, mas também pelos seguintes critérios: Fleiss und Aufmerksamkeilt (aplicação e concentração) e Schulbesuch (frequência escolar).

Os boletins contêm, ainda, um campo para mais atividades e habilidades avaliadas: Schreiben (escrita); Zeichnen (desenho); Turnen (Ginástica); Gesang (canto); Handarbeiten (trabalhos manuais). A Religian (religião) estava presente no boletim nesse campo, porém, escrita à mão com caneta tinteiro. Conforme Siedenberg (1952), o ensino de religião passou a ser livre a partir do momento em que a Sociedade Escolar Alemã assumiu a administração da escola (1912), o que possibilitava que católicos e luteranos fossem atendidos por seus respectivos sacerdotes.

De acordo com Siedenberg (1952, p. 12), em 1928 ocorreram mudanças no currículo escolar, quando o à época diretor Karl Sölter ${ }^{16}$, elaborou um programa de ensino que contava com as seguintes matérias: Português, alemão, inglês, História do Brasil, História Universal, Coreografia do Brasil, Geografia geral, Aritmética, Álgebra, Geometria, Física, Química, História Natural, Religião, Desenho, Canto, Trabalhos Manuais e Ginástica.

Quanto ao material didático, os livros e as cartilhas escolares salvaguardados no museu da escola sugerem que o principal material de apoio utilizado na instituição era bilíngue e direcionado para Escolas Alemãs no Brasil, sendo editado pela Editora Rotermund, em São Leopoldo. Kreutz (2007, p. 200), ressalta que essa era uma escolha usual de material didático por parte dos luteranos, enquanto os católicos adquiriam os seus principalmente na Typographia do Centro e na Livraria e Editora Selbach, ambas em Porto Alegre.

\footnotetext{
${ }^{16}$ O diretor Karl Sölter assumiu a direção da escola em 1928, permanecendo até o ano de 1934.
} 
Entre os títulos salvaguardados pela instituição, ressaltamos a cartilha intitulada Fibel für Deutsche Schulen in Brasilien (Cartilha para escolas alemãs no Brasil), e Orthoepia da da Lingua Portugueza em exercícios para as Escolas Allemãs no Brasil, ambas são de autoria de Rotermund (editor e presidente do Sínodo Riograndense), e alcançaram uma grande tiragem em suas sucessivas reedições (Kreutz, 2007), ficando bem conhecidas no meio teuto-brasileiro luterano.

A instituição também salvaguarda a cartilha Meine Bunte Fibel e as gramáticas intituladas Gramática completa da língua portuguesa em regras e peças práticas e Minha língua - Gramática portuguesa para uso nas escolas alemãs no Brasil. O acervo conta também com outras obras direcionadas ao ensino de Artimética como Schlüssel zur Praktischen Rechenschule in vier Seiten für deutsche Schulen in Brasilien - von Otto Büchler ; História do natural como Heimat- und Naturkunde für deutsche Schulen in Rio Grande do Sul ; e Religião a partir da obra Religionsbuch für evangelisch Schulen in Brasilien. Todo material didático mencionado foi editado pela Editora Rotermund \& Co. em São Leopoldo e Cruz Alta (Rio Grande do Sul).

Apesar da predominância da língua e dos valores germânicos no cotidiano escolar, a subvenção estatal impulsionou a sociedade escolar a "fazer jus" ao auxílio e em 1914, o diretor da escola Walter Mittag, submeteu-se a um concurso em que deveria realizar provas de português, aritmética, geometria, história e geometria do Brasil, obtendo aprovação (SIEDENBERG, 1952, p. 8).

Esses indícios referentes ao currículo escolar, disciplinas ensinadas e materiais de apoio, eram elementos constituintes da cultura escolar, nos dando pistas em relação à forma pela qual a instituição “organizava o saber”. De acordo com Magalhães (2014, p. 13), esta organização é feita em intersecção com discursos normativos, que pelos indícios localizados, eram marcados pelas características do bilinguismo, da preservação da língua e da cultura alemã e da confissão luterana, enquanto simultaneamente, a professora Maria Amorim visava cumprir sua missão nacionalizadora, tentando incutir valores patrióticos nas mentes infantis. Um espaço escolar com essas características consistia em um ambiente propício para a demarcação do duplo pertencimento característico dos teuto-brasileiros: nacionalidade alemã e cidadania brasileira. 
A análise dos boletins escolares salvaguardados no acervo, também possibilitou verificar que a língua alemã continuou presente no currículo até durante o período da Primeira Guerra Mundial, em que ocorreu a primeira ação nacionalizadora oficial no ano 1917. Nesse primeiro momento, as escolas étnicas do Rio Grande do Sul não foram significativamente afetadas e o uso da língua alemã não foi proibido, mas algumas escolas, especialmente as católicas sob orientação do Arcebispo de Porto Alegre, passaram a ministrar aulas somente em língua portuguesa, retomando o uso da língua alemã somente no final da guerra (ISAIA, 1992). Os registros apontam que a Escola Alemã não teve experiências traumáticas nesse período, porém, precisou alterar sua denominação para “Escola Moderna”.

De acordo com a professora Amorim, lecionar na instituição durante a Primeira Guerra foi desafiador:

Era preciso um equilíbrio de compreensão, discrição e respeito mútuo para mantermos entre os colegas alemães e os alunos descendentes germânicos uma perfeita atmosfera de harmonia e de camaradagem [...]. (MARIA AMORIN in SIEDENBERG, 1952, p. 31).

A professora permaneceu na escola até o ano de 1918, quando foi contratada pelo estado para lecionar em um grupo escolar. A missão de "aliciamento patriótico" foi mantida de 1918 a 1927 pela professora Hypólita Burter, e de 1928 a 1931 pela professora Amália Lange. Conforme já foi enfatizado, com exceção destas professoras subvencionadas pelo município, os demais 26 docentes que passaram pela instituição no período entre 1912 a 1938, tinham origem europeia sem formação específica tendo, em sua maioria, realizado seus estudos na Alemanha ou no Seminário de Professores criado pelo Sínodo Riograndense em 1909.

Não é nossa intenção, neste estudo, aprofundar as análises a respeito dos professores. Porém, consideramos pertinente ressaltar que a sistematização dos docentes que lecionaram na instituição contribui para investigações futuras, especialmente aquelas voltadas para trajetórias de vida, biografia e prosopografia. Esses dados podem ser encontrados em Siedenberg (1952), disponível para consulta no museu escolar da instituição. Conforme destacamos em estudo anterior (SILVA; FIGUEIREDO, 2016), os museus e memoriais escolares convertem-se em espaços fecundos para a 
realização de pesquisas prosopográficas, uma vez que tendem a salvaguardar informações diversas da vida dos sujeitos escolares.

A partir dos elementos aqui sistematizados, podemos perceber alguns aspectos organizativos, que moldavam e definiam a Escola Alemã e sua forma de pensar e atuar (VIÑAO FRAGO, 1996). Em 1938, em decorrência da implantação da política de nacionalização do ensino decretada pelo governo estadonovista, as adaptações feitas até o momento em relação ao ensino do vernáculo, e a introdução de valores nacionalistas brasileiros por parte das professoras pagas pelo município, não foram suficientes para impedir que a escola passasse por uma grande crise.

As novas políticas nacionalizadoras determinavam que todo material utilizado nas escolas elementares fosse em língua portuguesa, que todos os professores e diretores de escola fossem brasileiros natos, proibia a circulação de quaisquer textos, jornal ou revista em língua estrangeira e determinava instrução escolar adequada de história e geografia do Brasil. Além disso, era proibido o ensino de língua estrangeira a menores de 14 anos e tornou-se obrigatório dar destaque a bandeira nacional em datas cívicas e demais festividades, prestando sempre homenagem. As medidas atingiram inicialmente as escolas rurais, atingindo as demais escolas principalmente a partir de 1939 (KREUTZ, 1991).

A nacionalização do ensino deu início a um período de insegurança e temor na instituição. Apesar das adaptações feitas desde a década de 1910 por parte do município e da instituição, com a introdução do vernáculo e do ensino de história e geografia do Brasil, a diretoria e a maior parte do corpo docente era composta por professores de origem europeia, além dos materiais de apoio bilíngues utilizados, editados pela Editora Rotermund não serem mais aceitos. As novas exigências demandavam reformas significativas e urgentes, como a demissão dos professores e a volta do diretor Karl Köber para à Alemanha, já que pelas novas determinações ele não podia mais ocupar o cargo. Além disso, a escola perdeu muitos alunos, restando somente oito dos quase 200 matriculados no ano anterior (BRANDT, 2009). 
Com o cargo de diretor vago e a demissão dos professores, a ex-professora da Instituição, Sr. ${ }^{a}$ Amália Lange Löw ${ }^{17}$, que já estava aposentada, retornou à escola e assumiu a direção de forma emergencial, sendo de nacionalidade brasileira e formada no curso normal, preencheu a primeira das exigências. De acordo com Brandt (2009), a escola precisou utilizar de sua competência e criatividade para sobreviver a esse período. Uma das estratégias adotadas foi retomar o vínculo institucional com a Comunidade Evangélica de ljuí, que em 1938 veio a ser sua mantenedora. No mesmo ano a escola também passou a integrar o Sínodo Riograndense que passa a lhe prestar assessoria (BRAND, 2009, p. 15). A mudança também foi marcada pela troca de denominação que de "Colégio ljuiense", - apesar de conhecido na cidade como Colégio Alemão mudou para "Colégio Sinodal".

Em 1938, as aulas começaram 15 dias mais tarde e dos quase 200 alunos matriculados no ano anterior, só havia oito no início das aulas. Em 1939, a matrícula já aumentou para 32 alunos, mas a escola ainda estava longe de se reestabelecer (BRANDT, 2009). Os registros apontam que a escola teve dificuldades nesse período de adequação, mas que o estabelecimento não foi fechado e o papel do Sínodo Rio-grandense foi fundamental ${ }^{18}$.

\section{CONSIDERAÇÕES FINAIS}

O estudo buscou aproximações acerca da aplicação prática do projeto de colônia multiétnica de ljuí, através do âmbito educacional. A partir da análise do caso da primeira escola comunitária de origem germânica e confissão evangélica instalada na região foi possível perceber algumas questões.

Primeiramente, o cenário educacional estabelecido após a fundação da colônia, foi semelhante ao já encontrado nas "colônias velhas" ou "antigas": A escassez de recursos impôs a resolução de problemas mais urgentes como a organização de moradias e da produção de subsistência. Assim, o processo de escolarização só teve início quatro anos após a fundação da colônia através do impulso de um professor alemão que

\footnotetext{
${ }^{17}$ Ficou na direção somente de 1938 a 1939.

${ }^{18}$ Sobre as orientações do Sínodo Rio-grandense, e o papel do presidente Pastor Dohms nas negociações com o âmbito estatal, ver Dreher (2011) e Santos (2006).
} 
começou a dar aulas particulares em um espaço improvisado de ensino, sendo nomeado como primeiro professor público da região em 1905. Dessa forma, nos primeiros anos, o cenário proporcionado logo após a implantação da colônia não favoreceu o estabelecimento de um sistema educacional que assimilasse os imigrantes no contexto nacional.

Com a fundação de uma escola privada comunitária em 1899, pela Comunidade Evangélica local, a conotação étnica e a confissão luterana foram ainda mais reforçadas na região. A presença de uma comunidade evangélica e de uma "Escola Alemã" facilitava a manutenção de identidade teuto-brasileira, marcada nesse contexto pelo uso da língua materna e da confissão luterana.

A partir de 1912, com a emancipação da colônia, começamos a verificar uma maior preocupação do município com o âmbito educacional e o uso do vernáculo foi incentivado sob subvenção estatal, marcando o início da educação bilíngue, na Escola Alemã. A introdução da Língua Portuguesa e do ensino de História e Geografia do Brasil na instituição, ampliou a integração e o conhecimento dos estudantes sobre o contexto nacional, porém, conforme já mencionado, esses pequenos incentivos para uma suposta assimilação dos imigrantes não foram suficientes para evitar uma grande crise em decorrência da política de nacionalização do ensino.

Sem ter a intenção de esgotar a temática, acreditamos oferecer reflexões que contribuem para a construção do conhecimento em História da Educação, sobretudo em escala local. Além disso, oferecemos elementos para que estudos futuros possam ser realizados em diferentes temáticas, seja na História das Instituições Escolares, história do currículo escolar, relações de gênero e História da Educação, entre outras.

\section{REFERÊNCIAS}

ARAGÃO, Milena; FREITAS, Gonçalves Bueno de. Discursos morais no periódico "Folha da Escola” (1940): representações infantis. Revista Pedagógica, v.13, n. 26, p. 161-183, jan.jun. 2011.

BASTOS, Maria Helena Camara. Os jesuítas e a educação no Rio Grande do Sul: percurso histórico na formação das almas. In: SOUZA, Carlos Ângelo de Menezes; CAVALCANTE, 
Revista do Programa de Pós-Graduação em Educação da Unochapecó ISSN 1984-1566 (on-line) ISSN 1415-8175 (impressa)

Maria Juraci Maia (Org.). Os jesuítas no Brasil: entre a colônia e a República. Brasília: Líber Livro, 2016. p. 137-160.

BORCINI, Leonardo. O museu escolar do CEAP: Reflexões sobre a prática museal e a relação entre memória e história. 2012. 110f. Dissertação - (Mestrado em Ciências Sociais). Universidade Federal de Santa Maria, Santa Maria, 2012.

BRANDT, Mônica. CEAP- Colégio Evangélico Augusto Pestana trajetórias e lições de superação de uma escola: de sua criação (1899) até o fim do Estado Novo (1945). ljuí: Ed. Unijuí, 2009.

BRENDLER, Albino. Relatos do Sr. Albino Brendler [194 - 1950]. Tradução de Erica Ziegler. MECEAP: ljuí, 1995.

DREHER, Martin N. Igreja e germanidade: estudo crítico da história da Igreja Evangélica de Confissão Luterana no Brasil. São Leopoldo: EST/Sinodal, 2003.

ESCOLANO BENITO, Augustín. Memoria de la Educación y Cultura de La Escuela. In: ESCOLANO BENITO, Augustín; HERNÁNDEZ DÍAS, José Maria (Org.). La memoria y el deseo: Cultura de la escuela y educación deseada. Edita Tirant Lo Blanch, 2002.

ESCOLANO BENITO, Augustín. A escola como cultura: experiência, memória e arqueologia. Campinas, SP: Editora Alínea, 2017.

FALEIRO, Silvana Rossetti. Colégio Evangélico Alberto Torres: memórias e história. Lajeado, RS: UNIVATES, 2005.

GERTZ, René. O perigo alemão. Porto Alegre: Ed. da UFRGS, 1991.

ISAIA, Arthur Cesar. 0 cajado da ordem catolicismo e projeto político no Rio Grande do Sul: D. João Becker e o autoritarismo. 1991. 398f. Tese (Doutorado em História). USP, São Paulo, 1992.

JULIA, Dominique. A cultura escolar como objeto histórico. Revista Brasileira de História da Educação, n. 1, p. 9-44, jan. /jun., 2001.

KOCH, Walter. A escola evangélica teuto-brasileira. In: FIORI, Neide Almeida ; et al. (Org.). Etnia e educação: a escola "alemã" do Brasil e estudos congêneres. Florianópolis: Ed. Da UFSC, Tubarão: Editorial Unisul, 2003. p. 193- 207.

KREUTZ, Lucio. O professor paroquial: magistério e imigração alemã. Porto Alegre: Editora UFRGS, 1991.

KREUTZ, Lucio. Escolas comunitárias de imigrantes no Brasil: instâncias de coordenação e estruturas de apoio. In: Revista Brasileira de Educação. n. 15, set./out/nov., 2000, p. 159176. 
Revista do Programa de Pós-Graduação em Educação da Unochapecó ISSN 1984-1566 (on-line) ISSN 1415-8175 (impressa)

LUCA, Tania Regina de. Imigração e Teorias Antropológicas no Brasil (1910-1920). in: DREHER, Martin N.; RAMBO, Arthur Blásio Rambo; TRAMONTINI Maros Justos. Imigração \& imprensa. Porto Alegre EST/ São Leopoldo: Instituto Histórico de São Leopoldo, 2004. p. 35- 47.

MAGALHÃES, Justino Pereira de. Tecendo nexos: história das instituições educativas. Bragança Paulista: Editora Universitária São Francisco, 2004.

MEYER, Dagmar Elisabeth Estermann. Identidades traduzidas: cultura e docência teutobrasileiro-evangélica no Rio Grande do Sul. Santa Cruz do Sul: EDUNISC, São Leopoldo: Editora Sinodal, 2000.

MORCH, Maria Luiza Azevedo. A ideologia educacional brasileira como fator de integração forçada do descendente do imigrante alemão à cultura nacional: 1937-1945. 1988. 332f. Dissertação (Mestrado em História) - Programa de Pós-Graduação em História da Pontifícia Universidade Católica do Rio Grande do Sul, Porto Alegre, 1988.

NEUMANN, Rosane Marcia. Uma Alemanha em miniatura: o Projeto de imigração e colonização étnico particular da colonizadora Meyer no Noroeste do Rio Grande do Sul (1897-1932). 2009. 631f. Tese (Doutorado em História) - Programa de Pós-Graduação em História, Pontifícia Universidade Católica do Rio Grande do Sul, Porto Alegre, 2009.

NOSELLA, Paolo; BUFFA, Ester. Instituições escolares. Por que e como pesquisar. Campinas, SP: Editora Alínea, 2009.

POLLAK, Michael. Memória, Esquecimento, Silêncio. Estudos históricos, Rio de Janeiro, v. 2, n.3, p. 3-15, 1989.

PROST, Antoine. Doze Lições sobre História. Belo Horizonte: Autêntica Editora, 2015.

ROSA, André Schmidt da; TRENNEPOHL, Vera L; CARNEIRO, Elenise de. A história do aluno percebida na história de ljuí a constituição do "ser professor": refletindo sobre um diálogo estabelecido com alunos do ensino médio. In: Salão do Conhecimento, 2017, Ijui. Jornada de Pesquisa - Ciências Humanas. Ijui: Unijui, 2017. v. 1. p.1-9.

SANTOS, Rodrigo Luis. Palavras, ideias e tensões: as relações conflituosas entre o sínodo rio-grandense e a secretaria de educação do Rio Grande do Sul (1938-1943). Agora. Santa Cruz do Sul, v. 17, n. 02, p. 127-133, jul./dez. 2016.

SCHWARCZ, Lilia Moritz; STARLING, Heloisa Murgel. Brasil: Uma biografia. São Paulo: Companhia das Letras, 2015.

SIEDENBERG. Breve Histórico do Ginásio Evangélico Augusto Pestana: da escola da roça ao ginásio moderno. Elaborado por Henrique Siedenberg e organizado e traduzido por íris Zwanziger e Ulrich Löw. ljuí: Löw, 1952. 
SILVA, Eduardo Cristiano Hass da; FIGUEIREDO, Milene Moraes de. Traçando o perfil social de técnicos contabilistas: uma análise prosopográfica a partir de fontes encontradas no Memorial do Colégio Farroupilha de Porto Alegre/RS. História Unicamp, v. 3, n. 6, p. 451-462, 2016.

SILVA, Haike Rosane Kleber da. Entre o amor ao Brasil e ao modo de ser alemão: a história de uma liderança étnica (1868-1950). São Leopoldo: Oikos, 2006.

STEPHANOU, Maria; BASTOS, Maria Helena Camara. História, memória e História da Educação. In: STEPHANOU, M; BASTOS, M. H. C. (Org.). Histórias e Memórias da Educação no Brasil. v. III - Século XX: Vozes, 2005. p. 416-429.

VIÑAO FRAGO, Antonio. Sistemas educativos, culturas escolares y reformas. Madrid: Morata, 2006.

WACHHOLZ, Wilhelm; SCHMIDT, Jefferson. Preservando, reformulando e produzindo identidade teuta no Brasil através da escola. In: Anais do Congresso Internacional da Faculdade EST. São Leopoldo, EST, v. 1, 2012. p. 1624-1640.

WILLENS, Emílio. A aculturação dos alemães no Brasil. Estudo antropológico dos alemães e seus descendentes. São Paulo: Companhia Editora Nacional, 1946.

Recebido em: $30-05$ - 2021

Aprovado em: $25-06-2021$

Publicado em: 29 - 06 - 2021 